\title{
EL DISCURSO DEL POPULISTA COMO REIVINDICACIÓN LATINOAMERICANA EN EL ACTUAL DES-ORDEN HEMISFÉRICO'
}

\section{THE POPULIST'S SPEECH AS A LATIN-AMERICAN REIVINDICATION IN THE ACTUAL HEMISPHERIC DISORDER}

\begin{abstract}
ANDRÉS FELIPE GIRALDO DÁVILA. Magíster en Relaciones Internacionales de la Pontificia Universidad Javeriana y profesor de Geopolítica de la Facultad de Comunicación de la Universidad de Medellín. Email: afgiraldo@udem.edu.co
\end{abstract}

Fecha de recepción: 2 de febrero de 2010.

Fecha de aprobación: 1 de marzo de 2010.

Resumen: América Latina está viviendo una serie de antagonismos políticos auspiciados por discursos políticos que, al reproducirse por los medios masivos de comunicación, alimentan disputas y discordias que afectan la integridad de objetivos políticamente comunes para la región.

Abstrac: Latin America is living a series on political antagonisms supported by political speeches that, when reproducing by massive means of communication, disputes feed and discords that affect the integrity of politically common objectives for the region. 


\section{REVISTA VIRTUAL VIA INVENIENDI ET IUDICANDI \\ "CAMINO DEL HALLAZGO Y DEL JUICIO"}

http://viei.usta.edu.co/ E-MAIL: revistainveniendi@usantotomas.edu.co

Palabras clave: Populismo, neopopulismo, realismo, idealismo, gobernabilidad democrática, agenda-setting.

Key words: Populism, neoPopulism, realism, idealismo, democratic governability

Identificación del Artículo: Reflexión académica.

\section{INTRODUCCIÓN}

La estructura del sistema internacional se dinamiza, cambia y continúa a través de una línea divisoria de antagonismos políticos soportado en un eje discursivo que alimenta dichas fracturas, razón por la que el discurso político constituye un amplio dinamizador de las relaciones entre los Estados.

Analizar teóricamente las relaciones internacionales pone en relieve el movimiento pendular entre el realismo político y la postura idealista, caracterizado por medir las relaciones de conflicto y cooperación que se dan entre los Estados-nación. Este fue el supuesto que originó el proyecto de investigación denominado "El debate realismo-idealismo en la actual guerra contra el terror" ${ }^{11}$, ya que ambas

\footnotetext{
${ }^{1}$ Para consultar el proyecto de investigación para optar al título de magíster en Relaciones Internacionales, ver: Giraldo Dávila, Andrés Felipe (2006). "El debate realismo-idealismo en la actual guerra contra el terror", Pontificia Universidad Javeriana, Bogotá, 102 p. El eje central de la tesis de grado consistió en medir el
} 


\section{REVISTA VIRTUAL VIA INVENIENDI ET IUDICANDI \\ "CAMINO DEL HALLAZGO Y DEL JUICIO"}

http://viei.usta.edu.co/ E-MAIL: revistainveniendi@usantotomas.edu.co

posturas se han enfrentado en campos académicos de una forma tal, que han permitido reflexionar y enriquecer los campos de estudio de la política internacional.

La cooperación y el conflicto son dinámicas tan divergentes que supondría anticipar que la política internacional solo se podría explicar desde dos esferas separadas; no obstante, el vínculo entre ambas estructuras conllevó a concluir en la investigación que la cooperación y el conflicto se encuentran en una misma esfera, la cual dinamiza las relaciones entre los Estados.

Basado en los presupuestos explicativos de Hedley Bull en su célebre título "La sociedad anárquica: un estudio sobre el orden en la política mundial" y el clásico de Keneth Wlatz titulado "Teoría de la política mundial", se pudo establecer una comparación teórica sobre el comportamiento de los Estados-nación, siendo éstos los principales reguladores de la política internacional. Si bien los argumentos de ambos autores sirvieron para explicar el episodio de la de Guerra Fría, tanto la realpolitik defendida por Waltz, como los principios idealistas esbozados por Bull,

comportamiento, tanto conflictivo como cooperativo, por parte de Estados Unidos en la denominada Guerra Mundial contra el Terrorismo global desatada después de los atentados del 11 de septiembre de 2001. En la Estrategia de Seguridad Nacional de Estados Unidos en su versión del año 2002, el presidente George W. Bush dibujó un nuevo mapa en la geopolítica mundial al establecer nuevas agendas cooperativas para entrar en conflicto con actores catalogados dentro del denominado 'eje del mal'. Sin embargo, el análisis del presente artículo quiere extraer dicho escenario al campo hemisférico, ya que América Latina está viviendo una serie de antagonismos políticos auspiciados por discursos políticos que, al reproducirse por los medios masivos de comunicación, alimentan la llama de la discordia. 


\section{REVISTA VIRTUAL VIA INVENIENDI ET IUDICANDI \\ "CAMINO DEL HALLAZGO Y DEL JUICIO" \\ http://viei.usta.edu.co/ E-MAIL: revistainveniendi@usantotomas.edu.co}

sirven para explicar que hoy, en política internacional, la cooperación y el conflicto están presentes en una misma coyuntura.

El proceso metodológico que sirvió de guía para definir el supuesto planteado fue el análisis cualitativo del discurso político del presidente de los Estados Unidos George W. Bush plasmado en la Estrategia de Seguridad Nacional del año $2002^{2}$. Se estableció que, dentro de un mismo discurso existieron puntos sobre la articulación de nuevas alianzas cooperativas para enfrentar el terrorismo global luego de los atentados del 11 de septiembre de 2001. De esta forma, se diseñó un nuevo tablero en la geopolítica mundial con aliados y enemigos soportado en el discurso de la 'guerra preventiva' proclamada por Washington, donde la sociedad internacional defendida por Bull y el realismo político teorizado por Waltz soportan las bases discursivas del comportamiento exponencial de Estados Unidos como regulador de las relaciones internacionales.

Términos como el eje del mal, ellos contra nosotros, el bien contra el mal, herencia de los totalitarismos del siglo XX, Estados canallas, actores transnacionales que atentan contra los amantes del bien que desarrollan Armas de Destrucción Masiva $^{3}$, fueron los pilares cualitativos hallados dentro del discurso de la

\footnotetext{
${ }^{2}$ Para más precisión ver: www.state.gov/nss

${ }^{3}$ Un análisis más profundo del discurso de guerra preventiva es abordado por Kristol, William; Kagan, Robert (2005) Contra el eje del mal, Almuzara, España, 152 p.
} 


\section{REVISTA VIRTUAL VIA INVENIENDI ET IUDICANDI \\ "CAMINO DEL HALLAZGO Y DEL JUICIO"}

http://viei.usta.edu.co/ E-MAIL: revistainveniendi@usantotomas.edu.co

Estrategia de Seguridad Nacional de Estados Unidos, los cuales permitieron establecer el actual esquema de amigos y enemigos en la política internacional.

En este orden internacional pos 11 de septiembre, la difusión de los discursos políticos transmitidos a través de los medios masivos de comunicación constituye un elemento sustancial orientador sobre la percepción y el ambiente de las relaciones internacionales. Las relaciones de cooperación y conflicto son frecuentes dentro de los espacios propios de la agenda-setting ${ }^{4}$, concepto que explica las realidades que emanan de los medios masivos para configurar el imaginario de la opinión pública internacional.

Al respecto, en la atmósfera escénica de América Latina se respira un ambiente de cooperación con constantes rupturas conflictivas a la par, que no tienen línea divisoria sino que hacen parte de una misma esfera, tanto en lo discursivo como en la agenda pública, esta última con amplia cobertura en los espacios de la agenda-setting.

De esta forma, el presente artículo permite ajustar los presupuestos metodológicos y conceptuales que permitan analizar cualitativamente las relaciones públicas de cooperación y conflicto que se establecen en América Latina, los cuales se

\footnotetext{
${ }^{4}$ Uno de los aspectos para tener en cuenta es la frecuencia de conflictos y alianzas que son abordadas por los medios de comunicación de masas para orientar las tendencias de la opinión pública global. El término agenda-setting está ligado con la realidad expuesta a través de los medios de comunicación, quienes son los responsables de determinar la agenda pública.
} 


\section{REVISTA VIRTUAL VIA INVENIENDI ET IUDICANDI \\ "CAMINO DEL HALLAZGO Y DEL JUICIO"}

http://viei.usta.edu.co/ E-MAIL: revistainveniendi@usantotomas.edu.co

soportan en gran medida gracias a los discursos políticos populistas que líderes de la región, en especial la figura del Hugo Chávez, pronuncian aprovechándose de los amplios espacios que ofrece la sociedad de la información.

\section{EL ADVENIMIENTO POPULISTA}

El discurso de los líderes populistas que ha acaparado el escenario político de América Latina en un contexto posterior al 11 de septiembre de 2001 está enmarcado por una amplia oposición antisistémica; es decir, una fuerte crítica al poder dominante internacional, representado por el papel hegemónico que ha impulsado Estados Unidos con la proclama de Guerra Mundial contra el Terrorismo.

Nuevos populismos acentuados en el actual contexto latinoamericano, encabezados de forma puntual por la figura presidencial de Hugo Chávez Frías, son figuras antisistémicas que pregonan una amplia resistencia a la oligarquía internacional, ya que la reivindicación de los pueblos constituye el arma de un discurso diseñado para atentar contra la las élites de poder. La experiencia populista en el hemisferio ha dejado la imprenta de una estructura que siempre ha pretendido acabar con un pasado represivo contra la base social que es el pueblo. En consecuencia, la reivindicación populista pos 11 de septiembre pretende 


\section{REVISTA VIRTUAL VIA INVENIENDI ET IUDICANDI \\ "CAMINO DEL HALLAZGO Y DEL JUICIO"}

http://viei.usta.edu.co/ E-MAIL: revistainveniendi@usantotomas.edu.co

posicionar un antagonismo político frente a la doctrina estadounidense de enfrentar el terrorismo internacional.

"Ya tenemos dos claras precondiciones del populismo: (1) la formación de una frontera interna antagónica separando el pueblo del poder; (2) una articulación equivalencial de demandas que hace posible el surgimiento del pueblo. Existe una tercera precondición que no surge realmente hasta que la movilización política ha alcanzado un nivel más alto: la unificación de estas diversas demandas en un sistema estable de significación" (Laclau, 2005: 99)

Si bien la democracia goza de buena salud dentro de las sociedades latinoamericanas desde el punto de vista de la legitimidad como sistema político, el déficit de las instituciones representado en la pobreza, desigualdad, impunidad y concentración del poder, constituyen fuentes de conflicto en las relaciones hemisféricas producto de los desórdenes ocasionados por los desequilibrios que los sistemas políticos no han podido subsanar. La promoción de la democracia y la consolidación de la economía de mercado han sido políticas implementadas en América Latina para el establecimiento de las buenas relaciones cooperativas desde los años noventa, lo que ha permitido un impulso del crecimiento y desarrollo humano en los ciudadanos del Continente. No obstante, la aplicación de estos modelos ha acentuado la inequidad y el desorden social, situación propensa a ser aprovechada por líderes políticos que pregonan discursos populistas 


\section{REVISTA VIRTUAL VIA INVENIENDI ET IUDICANDI \\ "CAMINO DEL HALLAZGO Y DEL JUICIO"}

http://viei.usta.edu.co/ E-MAIL: revistainveniendi@usantotomas.edu.co

orientados a impulsar un conflicto desestabilizador dentro del sistema político hemisférico.

Las amplias demandas sociales hacia la democracia ha hecho que la ciudadanía en algunos Estados de la región sufran un amplio descontento social, lo que acentúa el desorden político, económico y social en amplios contextos latinoamericanos, lo que a la postre ha desencadenado una saturación tal del sistema, que el surgimiento de líderes populistas emerge como el remedio a las deficiencias propias de la democracia, escenario propicio para que el discurso de este tipo de líderes ataque el sistema democrático oligárquico y se consolide un cambio en el orden político.

[... el populismo es vago e indeterminado tanto en el público al que se dirige y en su discurso, como en sus postulados políticos; es mera retórica...la vaguedad y la indeterminación no constituyen defectos de un discurso sobre la realidad social, sino que, en ciertas circunstancias, están inscriptas en la realidad social como tal...] (Laclau, 2005: 91)

El discurso del líder populista se realiza de forma verticalista con el objeto de reivindicador las demandas populares a través del ataque hacia la clase política habitual o tradicional. Los elementos que componen dicho eje discursivo no tienen parámetros de lenguaje preexistentes, sino que configuran la forma en que la 


\section{REVISTA VIRTUAL VIA INVENIENDI ET IUDICANDI \\ "CAMINO DEL HALLAZGO Y DEL JUICIO"}

http://viei.usta.edu.co/ E-MAIL: revistainveniendi@usantotomas.edu.co

relación social debe conjugar los factores que rigen las relaciones sociales. Para el caso latinoamericano póstumo al 11 de septiembre, el discurso político opositor a la Estrategia de Estados Unidos no es seguir el conducto de la democracia y el mercado para enfrentar al terrorismo como estructura estratégica de agenda pública, sino la lucha contra las élites de poder que han consolidado un Estado oligárquico opresor contra el pueblo latinoamericano. A través del discurso populista, la división del escenario social se realiza desde dos campos ampliamente antagónicos, "el régimen, la oligarquía, los grupos dominantes, para el enemigo; el pueblo, la nación, la mayoría silenciosa, para los oprimidos" (Laclau, 2005: 114), agudizan el desorden político de un continente dispuesto políticamente a escenificar elementos del conflicto en detrimento de un proyecto cooperativo entre los Estados de la región. "Es una respuesta popular a una crisis política del Estado (ineficiencia, clientelismo, altos niveles de corrupción); a la deslegitimación de unas elites que dejaron de entender las nuevas realidades..." (Sanjuan, 2007: 4).

El caos y desorden que producen los fenómenos populistas y sus componentes discursivos, "incluyen a unos grupos, es decir, se representan, pero también se excluyen otros" (Márquez, 2000: 77), es decir, atacan y marginan, situación que provoca una agudización crítica de la gobernabilidad democrática en América Latina, lo que origina una desmembración de las relaciones cooperativas propias de la sociedad internacional defendidas dentro de los principios teóricos de Hedley 


\section{REVISTA VIRTUAL VIA INVENIENDI ET IUDICANDI \\ "CAMINO DEL HALLAZGO Y DEL JUICIO"}

http://viei.usta.edu.co/ E-MAIL: revistainveniendi@usantotomas.edu.co

Bull, incrementando un notorio realismo político que se presupuesta dentro de las posturas de Kenneth Waltz. El advenimiento de fenómenos populistas junto a su componente discursivo-retórico es el nuevo escenario dentro del movimiento pendular que confirma un dilema relacional entre cooperación y conflicto.

Pese a que América Latina se ha despojado del otrora fantasma de las dictaduras, las cuales se consolidaron en muchos países del Hemisferio en la segunda mitad del siglo XX como respuesta a los regímenes populistas-autoritarios o populistasburocráticos, en la actual coyuntura mundial es poco factible que en un futuro próximo o lejano, las dictaduras vuelvan a tomar el poder de los Estados. Sin embargo, las actuales democracias evidencian una seria amenaza sustitutiva: el neopopulismo como resistencia a parámetros dominantes en el actual sistema internacional posterior al 11 de septiembre donde la estructura preponderante es la lucha contra el terrorismo global.

Históricamente el populismo ha estado presente como estructura política y se cree que es de las doctrinas más originales de los latinoamericanos. Desde las primeras décadas del siglo, el populismo llegó para quedarse por mucho tiempo en varios países; ejemplos de ello el mexicano Partido Revolucionario Institucional (PRI), el populismo autoritario como el de Juan Domingo Perón y Getulio Vargas en Brasil. Dichos gobiernos se consolidaron para enfrentar el sistema oligárquico que había dominado la esfera institucional desde el mismo momento de la 


\section{REVISTA VIRTUAL VIA INVENIENDI ET IUDICANDI \\ "CAMINO DEL HALLAZGO Y DEL JUICIO"}

http://viei.usta.edu.co/ E-MAIL: revistainveniendi@usantotomas.edu.co

independencia. De ahí que uno de los rasgos fundamentales del populismo clásico haya sido el antagonismo entre una coalición multiclasista compuesta por grupos de sectores marginales, clases medias y elitistas disidentes para enfrentar a la clase oligárquica, añadiendo que tal coalición se aferraba a las virtudes mesiánicas configuradas en un líder, quien al mismo tiempo que enfrentó a los privilegiados, fue incorporando masiva y progresivamente al 'pueblo' dentro del proyecto modernizador de Estado. "El interés del populismo radicó en la incorporación de las masas como cuestión central por resolver, en un esquema inclusivo, las más de las veces en formas corporativas y clientelistas." (Walter: 2006).

Aunque se puede considerar que el populismo latinoamericano ha contenido algunos rasgos democráticos como suplir las demandas de los menos favorecidos, pujar por una mayor igualdad de derechos de los ciudadanos y lograr que las personas obtengan beneficios derivados del desarrollo económico, estos, al haberse caracterizado por su verticalidad pragmática, lograron cooptar a los principales representantes coaliados estableciendo nuevos privilegios y configurando un autoritarismo poco benéfico para los ciudadanos. En el continente escasamente hubo democracia... "pero lo cierto es que lo que sí hubo en América Latina fue populismo, o cierto modelo "nacional y popular". (Walter: 2006). Además, desde el punto de vista económico, el populismo clásico de Latinoamérica se caracterizó por la industrialización mediante la sustitución de las 


\section{REVISTA VIRTUAL VIA INVENIENDI ET IUDICANDI \\ "CAMINO DEL HALLAZGO Y DEL JUICIO"}

http://viei.usta.edu.co/ E-MAIL: revistainveniendi@usantotomas.edu.co

importaciones en donde el Estado de bienestar fue quien rigió las condiciones macroeconómicas para incorporar la población a la causa nacional, situación que a la postre derivaría en la irresponsabilidad fiscal, déficit y clientelismo.

Dicho contexto produjo una inflexión populista dejando a su haber una reacción aún mucho más radical: las dictaduras o derechización del populismo. Casos como el argentino, uruguayo, chileno o peruano sirven para ilustrar tal fenómeno. Las dictaduras inyectaron una dosis de privación de las libertades que frenaron los tímidos avances democráticos que se habían alcanzado hasta los años cincuenta y promulgaron un amor por el mercado representado por la ideología del liberalismo clásico. Los regímenes autoritarios aplicaron al pie de la letra las ventajas ofrecidas por el liberalismo incorporando y comprometiendo seriamente las economías a un mercado internacional. Como explica Walter (2006) el liberalismo siempre estuvo auspiciado por élites más que por pueblo, entendiendo al 'pueblo', en palabras de Laclau $(2005,108)$ como el cuerpo de todos los ciudadanos o los menos privilegiados. Este auspicio liberal de una clase dominante hizo prever que el ideario liberal ha ido más de la mano del autoritarismo que de la democracia. $Y$ es que a las dictaduras se les ha otorgado el no despreciable honor de haber sido quienes insertaron a algunas naciones latinoamericanas al mercado internacional, como en Chile bajo la dictadura de Augusto Pinochet o Panamá con Torrijos, este último con el proyecto de nacionalizar el Canal (Tagle: 2004, 39). Eficiencia fiscal, estabilidad inflacionaria, 


\section{REVISTA VIRTUAL VIA INVENIENDI ET IUDICANDI \\ "CAMINO DEL HALLAZGO Y DEL JUICIO"}

http://viei.usta.edu.co/ E-MAIL: revistainveniendi@usantotomas.edu.co

política macroeconómica desarrollista de la mano con una serie de reducciones a los privilegios de las clases trabajadoras, fueron algunos de los matices de la postura economicista de los regímenes dictatoriales.

Sin embargo, el mal desempeño de las dictaduras radicalizaron aún más las desigualdades sociales porque de un lado los pueblos fueron sometidos a serias violaciones de sus derechos y la inserción económica internacional impactó sobre el empleo y la inflación, situación que, en muchos de los casos obligó a los dictadores a dejar el poder y afirmar una demanda que pedían a gritos los ciudadanos y el sistema internacional: democracia. Además, si se tiene en cuenta que la dictadura convergió en una coyuntura de Guerra Fría, para Estados Unidos resultó de vital importancia que el hemisferio abandonara los regímenes militaristas.

La democracia apareció como tabla de salvación para evitar populismos, dictaduras o cualquier forma autoritaria de llegar al poder. Sin embargo, el problema que padeció la endeble democracia latinoamericana de los años ochentas fue enfrentar los embates producidos por una reforma que se le debía dar el Estado, que en muchos de los casos resultaron de corto plazo y aumentaron los problemas estructurales del hemisferio. De un papel dominante del Estado en la planificación, coordinación y ejecución de políticas económicas, se dio paso a la apertura de las economías en donde unos flujos de capitales cada vez más sólidos 


\section{REVISTA VIRTUAL VIA INVENIENDI ET IUDICANDI \\ "CAMINO DEL HALLAZGO Y DEL JUICIO"}

http://viei.usta.edu.co/ E-MAIL: revistainveniendi@usantotomas.edu.co

en el escenario internacional degeneraron en inestabilidad, crisis fiscal, aumento de la deuda externa e inflación, por lo que los gobierno cada vez más estuvieron comprometidos con las exigencias impuestas por el mercado de capital y tuvieron que aplicar al pie de la letra las recetas del Fondo Monetario Internacional para salir de tales fenómenos que estaban impactando el crecimiento de los países: privatización, flexibilidad laboral y menor injerencia de los Estados en la planificación económica. La Argentina de Menem experimentó dicho fenómeno, ya que el tránsito de la dictadura a la democracia de Alfonsín derivó en una cadena de medidas cortoplacistas agudizando crisis que Carlos Menem tuvo que capotear así previamente haya acudido a retóricas populistas para llegar al poder. En igual sentido Perú, que tras haber pasado a la democracia al inicio de los setenta dicho proyecto quedó expuesto a los vaivenes del mercado e inestabilidad institucional, por lo que Alan García, el primer miembro del APRA en llegar al poder, acudió a la misma retórica populista de partido para prometer mejoras que nunca se dieron y por el contrario realizar una más notoria aplicación liberal que cobijaría prácticas corruptas desestabilizadoras para los peruanos. Lo mismo se puede decir de Carlos Andrés Pérez en Venezuela, quien decidió "cortar bruscamente con su pasado político y emprender una reforma del Estado de corte neoliberal, o al ex presidente de Bolivia, Víctor Paz Estenssoro, antiguo caudillo de la revolución estatista de 1952, asumiendo un rol privatizador de la economía de su país." (Tagle: 2004, 52). 


\section{REVISTA VIRTUAL VIA INVENIENDI ET IUDICANDI \\ "CAMINO DEL HALLAZGO Y DEL JUICIO"}

http://viei.usta.edu.co/ E-MAIL: revistainveniendi@usantotomas.edu.co

Esta serie de fenómenos ha descubierto una paradoja sin igual en el ámbito político latinoamericano y es que los gobernantes utilizaron previamente rasgos populistas, como la imagen del líder carismático que representaba al pueblo, discursos de reconciliación nacional y una vuelta a la importancia del Estado, para ser elegidos democráticamente. Menem con su imagen gaucha surgió desde la provincia de La Rioja para salvar al pueblo argentino; García y Collor de Melo con sus figuras apuestas pretendieron unir a sus pueblos en una causa nacional. Solo que, ante las exigencias de un contexto internacional sediento de ubicar capitales y agudizando crisis económicas a su antojo demeritó en primera instancia dichos proyectos benévolos e hizo revocar los comportamientos de aquellos líderes que no tuvieron más escapatoria que aplicar privatizaciones, alejar al Estado del proyecto nacional y dejar a sus naciones a expensas de la inferencia liberal que con anterioridad sus antagónicos dictadores habían aplicado del mismo modo.

Quizás se puede argumentar que a la democracia se le ha exigido más de lo que puede dar, razón por la que si bien el continente goza de tal régimen en cuanto a receptividad $^{2}$, el panorama aún es muy exigente para la efímera democratización que se ha dado. Es por esto que, a la sombra se mantiene expectante un nuevo populismo de corte más radical y que pretende devolverle al pueblo de las naciones las promesas incumplidas que nadie ni ningún paradigma político les ha podido entregar. 


\section{REVISTA VIRTUAL VIA INVENIENDI ET IUDICANDI \\ "CAMINO DEL HALLAZGO Y DEL JUICIO" \\ http://viei.usta.edu.co/E-MAIL: revistainveniendi@usantotomas.edu.co}

Si antes el populismo apareció para luchar contra las oligarquías dominantes, ahora, en el nuevo orden internacional, el populismo está apareciendo en América Latina para demandar mayor igualdad, mayores derechos ciudadanos en un contexto en el que las pautas del liberalismo, moralmente les pueda servir a los pueblos para su reivindicación. El neopopulismo "surge de la extendida realidad de la pobreza, la desigualdad y la desesperanza, expresadas todas ellas, más allá de las cifras o estadísticas, en aquel elocuente graffiti escrito en algún muro de Lima, Perú, y que nos ahorra muchos comentarios: "No más realidades, queremos promesas." (Walter: 2006). Este nuevo populismo promulga una responsabilidad fiscal y temor por la inflación, pero ante todo, si bien no descarta las alianzas derivadas del mercado, pretende devolverle al pueblo esas ventajas que históricamente ha dejado el liberalismo por medio de la doctrina de la 'nacionalización de la producción'.

El neopopulismo es una reivindicación de temas sociales como la exclusión, que se ha traído a colación en el torrente discursivo de los líderes que abanderan un nuevo proyecto nacional popular; concibe la economía conforme a las exigencias de la estabilidad, la eficiencia y la justicia en dirección al bien común; defiende las iniciativas individuales que conllevan a la riqueza y sostiene una distribución justa de esta para insertarla en el sistema económico; trae a colación nuevos beneficios a la clase trabajadora en pro de la dignificación de una clase arrasada por los golpes neoliberales; y, en primacía, le devuelve al Estado un papel central en la 


\section{REVISTA VIRTUAL VIA INVENIENDI ET IUDICANDI \\ "CAMINO DEL HALLAZGO Y DEL JUICIO"}

http://viei.usta.edu.co/ E-MAIL: revistainveniendi@usantotomas.edu.co

conducción de los anteriores proyectos reivindicadores ${ }^{3}$. No obstante, la verticalidad con que se dirigen las conductas populistas hace que la democracia se vea amenazada porque entra en escena una práctica autoritaria que sustituye los partidos políticos, establece coaliciones a beneficio del aparato burocrático y dicho autoritarismo es legitimado por la vía democrática 'no apta'. En este escenario populista, se realza la democracia participativa en detrimento de una democracia representativa cada vez más influenciada por una sola figura y no por un colectivo que representa los más nobles intereses de los Estados.

El autoritarismo democrático es la mayor amenaza que impone ese nuevo populismo que se ha hecho evidente en América Latina; Hugo Chávez en Venezuela, Néstor Kirchner en Argentina, Tavaré Vásquez en Uruguay, Evo Morales en Bolivia y Luis Ignacio Lula da Silva en Brasil apuntan en esta dirección de reivindicar a sus sociedades distribuyendo la riqueza, nacionalizando (aunque no todos sino Chávez y Morales) sus producciones, estableciendo coaliciones entre ellos ante una postura antiestadounidense, pero sin dejar de lado el neoliberalismo estrechamente relacionado con ellos. El neopopulismo juega con abrir mercados y distribución equitativa, es un nuevo 'regionalismo abierto' para consolidar todo un frente socialdemócrata latinoamericano unido para enfrentar la pobreza, activar el crecimiento e instaurarse como potencia regional en bloque ante el mundo. Sin embargo, la aparición de un nuevo populismo afecta la gobernabilidad democrática, desvirtuándola, cooptándola y propiciando una 


\section{REVISTA VIRTUAL VIA INVENIENDI ET IUDICANDI \\ "CAMINO DEL HALLAZGO Y DEL JUICIO"}

http://viei.usta.edu.co/ E-MAIL: revistainveniendi@usantotomas.edu.co

ruptura tal, que dentro de las relaciones hemisféricas, la cooperación se ve fracturada y el conflicto tiene a agudizarse.

\section{CONCLUSIÓN: HACIA UN DISCURSO DE LA GOBERNABILIDAD DEMOCRÁTICA QUE REIVINDIQUE LA COOPERACIÓN LATINOAMERICANA}

La gobernabilidad es un modelo de legitimidad para solucionar la forma de gobernar, situación que en América Latina se le ha dado a la democracia en su tránsito atropellado a la misma. La democracia ha sido el modelo que ha sustituido a las dominaciones que antes se experimentaban con las dictaduras 0 autoritarismos, por lo que goza de un grado no despreciable de legitimidad en el contexto social latinoamericano. En consecuencia, el conjunto de desigualdades que ha hecho más pobre a los ciudadanos del hemisferio y las demandas insatisfechas de la democracia, ha hecho que este sistema político se esté debilitando, permitiendo el surgimiento del populismo como alternativa viable a los regímenes democráticos.

Las características principales de una gobernabilidad democrática son, en primer lugar, la consolidación de los gobiernos constitucionales, que en el continente ha sido bien ejecutado tras la ausencia de dictaduras otrora exitosas. Se celebra con cierto agrado la supremacía civil sobre las Fuerzas Armadas. Pese a todos los problemas de la deuda en América Latina, ningún gobierno -a excepción de 


\section{REVISTA VIRTUAL VIA INVENIENDI ET IUDICANDI \\ "CAMINO DEL HALLAZGO Y DEL JUICIO"}

http://viei.usta.edu.co/ E-MAIL: revistainveniendi@usantotomas.edu.co

Mahuad en Ecuador- fue derrocado por golpe militar (Domínguez y Shifter: 2005, 389).

En segunda instancia, una legítima balanza de poderes entre el Ejecutivo, el Legislativo y el Judicial, ya que es fundamental no dejar que mediante decretos el presidencialismo se imponga ante los intereses particularistas en el que el Congreso debe cumplir una labor planificadora, coordinadora y vigilante, y el judicial debe evidenciar una clara independencia. Sin embargo, en lo noventa, América Latina experimentó enjuiciamientos por parte del Congreso al régimen constitucional (Domínguez y Shifter: 2005, 390).

En tercer lugar, los partidos políticos tienen que jugar un papel predominante en las democracias porque son quienes articulan y agregan las demandas de la sociedad, son quienes organizan la vida parlamentaria tanto en el respaldo $u$ oposición gubernamental y negocian entre sí para reducir los conflictos de intereses. Es evidente el peligro que los partidos han experimentado en Venezuela o Perú en los periodos de Chávez y Fujimori quienes los han cooptado, suprimido y manipulado para beneficio del Ejecutivo. O qué decir del futuro que le espera a los partidos tradicionales colombianos tras el reciente triunfo de Álvaro Uribe en las elecciones presidenciales. 


\section{REVISTA VIRTUAL VIA INVENIENDI ET IUDICANDI \\ "CAMINO DEL HALLAZGO Y DEL JUICIO"}

http://viei.usta.edu.co/ E-MAIL: revistainveniendi@usantotomas.edu.co

En cuarto lugar, es importante la influencia de la clase trabajadora en la consolidación de sus derechos en un mundo globalizado. En épocas populistas, los sindicatos eran la base del poder que los líderes defendían para el proyecto nacional por lo que el beneficio a esta clase fue sumamente oneroso. Ahora, con las privatizaciones, la apertura y la reducción paulatina del poder sindical, estos deben reorganizarse y enfrentar los desafíos de la planificación en un mercado abierto y flexible.

En quinto lugar, la igualdad de género ha sido uno de los avances más significativos de la gobernabilidad democrática, ya que esta variable ha sido una de las más críticas que ha mantenido a Latinoamérica dentro de altos índices de desigualdad. "La democracia ha permitido que el papel político de la mujer sea más claro, amplio y positivo." (Domínguez y Shifter: 2005, 407).

Finalmente, uno de los grandes desafíos para la gobernabilidad democrática lo constituye el deseo de muchas burocracias de cambiar las reglas de juego por la vía constitucional para asegurarse ventajas, triunfos, amplio margen de maniobra y permanencia en el poder. "Los políticos creían que había que cambiar las reglas fundamentales con el fin de enfrentarse a una crisis profunda y generalizada durante el último cuarto de siglo." (Domínguez y Shifter: 2005, 408). 


\section{REVISTA VIRTUAL VIA INVENIENDI ET IUDICANDI \\ "CAMINO DEL HALLAZGO Y DEL JUICIO" \\ http://viei.usta.edu.co/ E-MAIL: revistainveniendi@usantotomas.edu.co}

A manera de conclusión, el discurso de los líderes políticos que optan por la reivindicación de la democracia como sistema político se debe ejecutar a partir del apego a los principios que rigen la democracia: consolidación institucional, imperio de la ley y libre expresión, ésta última como eje articulador que consolide las relaciones sociales de los ciudadanos del Continente.

El arribo de caudillos que usan la vía democrática para cambiar las reglas de juego una vez sentados en el poder no debe ser el camino propicio porque se incrementan los conflictos y antagonismos políticos en las sociedades latinoamericanas. La gobernabilidad democrática es legitimadora del sistema en la medida que canalice los límites que tienen las ramas del poder público y no utilizar éstas para establecer conflictos y beneficios particulares. Se debe respetar los regímenes constitucionales y alejarse de cualquier tentativa de deposición de gobiernos por la vía militar o de Congreso, ya que afectaría de facto a la democracia. Y finalmente, el papel de partidos políticos responsables, que no realicen colaciones de corto plazo, convenientes y con políticas 'al debe' es fundamental para avivar una democracia tan cuestionada en el último tiempo.

El afianzamiento de la gobernabilidad democrática, con todas sus variables y beneficios que trae consigo al establecer consensos acordados, es la mejor estrategia para enfrentar el advenimiento del fantasma del populismo que 


\section{REVISTA VIRTUAL VIA INVENIENIDI ET IUDICANDI \\ "CAMINO DEL HALLAZGO Y DEL JUICIO"}

http://viei.usta.edu.co/ E-MAIL: revistainveniendi@usantotomas.edu.co

históricamente ha rondado la esfera política de las endebles, pero no por eso menos eficaces, democracias latinoamericanas.

\section{BIBLIOGRAFIA}

DOMINGUEZ, Jorge; SHIFTER, Michael. Construcción de la gobernabilidad democrática en América Latina. Fondo de Cultura Económica, Bogotá, 2005.

LACLAU, Ernesto. La razón populista. Fondo de Cultura Económica, Buenos Aires, 2005.

MÁRQUEZ RESTREPO, MARTHA LUCÍA. Neopopulismo y chavismo. En: CONSUELO AHUMADA, TELMA ANGARITA, (Org.). La región andina entre los nuevos populismos y la movilización social, Bogotá, 2003, p. 65-123.

TAGLE SALAS, Alejandro. "El populismo en América Latina: la experiencia de caudillos de formación militar Perón, Velasco Alvarado y Chávez". Documentos de Gestión Pública de la Universidad Central de Chile, No 7, marzo de 2004.

WALKE, Ignacio. "Democracia en América Latina. Foreign Affaire en Español, Abril-junio 2006. Consultado en: http://www.foreignaffairs-esp.org/ 


\title{
REVISTA VIRTUAL VIA INVENIENDI ET IUDICANDI \\ "CAMINO DEL HALLAZGO Y DEL JUICIO"
}

http://viei.usta.edu.co/ E-MAIL: revistainveniendi@usantotomas.edu.co

\begin{abstract}
ROMANI, Azucena. "América Latina: la vuelta del populismo" En: http://weblogs.elearning.ubc.ca/peru/archives/025731.php
\end{abstract}

\footnotetext{
${ }^{1}$ Producto de una reflexión sobre la situación latinoamericana en un contexto de polarización política producto de la Guerra Mundial antiterrorista, tomando los argumentos de la tesis de maestría en Relaciones Internacionales "El debate realismo-idealismo en la actual guerra contra el terror”, Pontificia Universidad Javeriana, Bogotá, 2006. El artículo fue presentado en la ponencia bajo el mismo título en el marco de "Encuentro de ciencias sociales y humanas: derechas e izquierdas en el mundo contemporáneo", Universidad de Medellín, 29 y 30 de octubre de 2009.

2 "No hay que menospreciar lo que hemos logrado en términos de democratización. Las 12 elecciones que tendrán lugar hasta finales de 2006 son la demostración más elocuente de lo anterior. El Informe Latinobarómetro 2005 muestra que, a pesar de todo, existe una alta valoración de la democracia, la que coexiste con altos niveles de insatisfacción. El Informe PNUD 2005 señala que "la democracia se ha convertido en el sistema político dominante en América Latina", destacando que "casi todos los países de América Latina son democracias electorales en funcionamiento". El Freedom House 2006 indica que, hoy por hoy, todos los países de América Latina son democracias electorales, con las excepciones de Cuba y Haití (hay quienes califican a este último país simplemente como un caso de "estado fallido")." En: Walter (2006).

${ }^{3}$ Escobar Armas, Carlos. Economía populista mixta, economía social de mercado y neoliberalismo. En: http://www.asies.org.gt/m1997.htm
} 